\title{
Corrigendum: A Novel Test of Pure Irrelevance-Induced Blindness
}

\author{
Christian Büsel*, Thomas Ditye, Lukas Muttenthaler and Ulrich Ansorge \\ Faculty of Psychology, University of Vienna, Vienna, Austria
}

Keywords: attention capture, priming, load theory, irrelevance-induced blindness, continuously cumulative meta-analysis

\section{A Corrigendum on}

A Novel Test of Pure Irrelevance-Induced Blindness

by Büsel, C., Ditye, T., Muttenthaler, L., and Ansorge, U. (2019). Front. Psychol. 10:375. doi: $10.3389 /$ fpsyg.2019.00375

In the original article, there was an error. We stated that there was no difference in participants' correct first fixation between relevant and irrelevant rings whereas there were quantitatively more fixations on relevant than irrelevant disks. However, as can be seen in Table 3, we interchanged the ring and disk condition in the text. Similarly, in our discussion, we stated that the differences between relevant and irrelevant ring and disk conditions were identical in our explicit and implicit memory measures. However, implicit and explicit memory measures exhibit numerically opposite patterns. While the difference in the ring condition of our implicit memory measure is not statistically reliable, conjectures that are be based on the wrong rendering of the relationship between implicit and explicit memory measures might be incorrect, too.

Corrections have been made to Results, Implicit Memory Measure, Paragraph 1:

Ninety-three participants fixated at least one of the two colored stimuli during its presentation in the retrieval display. As can be seen in Table 3, similar to the explicit memory performance there were quantitatively more fixations on relevant than irrelevant ROIs. This difference was-in contrast to the explicit memory performance-slightly more pronounced in the ring condition. As with participants' accuracy of manual responses, we collapsed the various combinations of encoding versus retrieval displays into congruent and incongruent conditions (Table 4).

The authors apologize for this error and state that this does not change the scientific conclusions

Received: 08 October 2020

Accepted: 19 October 2020

Published: 17 November 2020

Citation:

Büsel C, Ditye T, Muttenthaler L and

Ansorge U (2020) Corrigendum: A

Novel Test of Pure Irrelevance-Induced

Blindness. Front. Psychol. 11:615123.

doi: 10.3389/fpsyg.2020.615123

Copyright (c) 2020 Büsel, Ditye, Muttenthaler and Ansorge. This is an open-access article distributed under the terms of the Creative Commons Attribution License (CC BY). The use, distribution or reproduction in other forums is permitted, provided the original author(s) and the copyright owner(s) are credited and that the original publication in this journal is cited, in accordance with accepted academic practice. No use, distribution or reproduction is permitted which does not comply with these terms. 